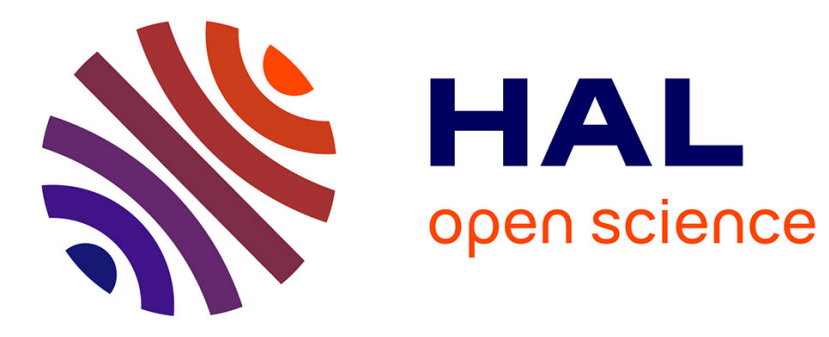

\title{
Double external cavity laser diode for DWDM applications
}

\author{
A. Laurent, P. Chanclou, M Thual, J Lostec, M Gadonna
}

\section{To cite this version:}

A. Laurent, P. Chanclou, M Thual, J Lostec, M Gadonna. Double external cavity laser diode for DWDM applications. J. Opt. A: Pure Appl. Opt., 2000, 2, pp.6 - 8. hal-02920581

\section{HAL Id: hal-02920581 \\ https://hal.science/hal-02920581}

Submitted on 24 Aug 2020

HAL is a multi-disciplinary open access archive for the deposit and dissemination of scientific research documents, whether they are published or not. The documents may come from teaching and research institutions in France or abroad, or from public or private research centers.
L'archive ouverte pluridisciplinaire HAL, est destinée au dépôt et à la diffusion de documents scientifiques de niveau recherche, publiés ou non, émanant des établissements d'enseignement et de recherche français ou étrangers, des laboratoires publics ou privés. 


\title{
LETTER TO THE EDITOR \\ Double external cavity laser diode for DWDM applications
}

\author{
A Laurent, P Chanclou, M Thual, J Lostec and M Gadonna \\ France Telecom, CNET, DTD/PIH, 2 avenue Pierre Marzin, 22307 Lannion Cedex, France \\ E-mail: monique.thual@cnet.francetelecom.fr \\ Received 17 September 1999, in final form 19 October 1999 \\ Abstract. A balanced dual-wavelength external cavity laser diode operating at $1.3 \mu \mathrm{m}$ is \\ reported with a side-mode suppression ratio of $>35 \mathrm{~dB}$. The construction of this laser is \\ based on a double external cavity using a 1:2 coupler and two different Bragg reflectors \\ photo-written within each channel. Thanks to the photo-written external cavity behaviour, a \\ laser with more than eight channels could be considered.
}

Keywords: Extended cavity, laser diode, dual wavelength, micro-optics, Bragg reflectors, optical communications, fibre optics components

\section{Introduction}

Over the last few years several methods have been studied to provide multi-wavelength sources for WDM applications. Much effort has been focused on dual and multiple wavelength operation with a self-seeding approach, based on wavelength selection in a distributed Bragg reflector (DBR) laser [1], or in an external cavity [2]. This selective function is achieved by either distinct diffraction gratings [3], or photo-written Bragg reflectors. Both Bragg reflectors can be used in series [4], or singularly in association with an interferometer [5]. In our device, two Bragg reflectors are separated with a coupler and their efficiency is controlled with two variable attenuators. Consequently, their respective wavelength output power is adjustable and can be balanced.

\section{Operating principles}

To demonstrate the feasibility of a multiple external cavity laser (MECL), we first studied the working characteristics of a single external cavity laser (SECL). The cavity is defined by the back facet of a Fabry-Perot laser diode (FPLD) operating near $1.3 \mu \mathrm{m}$ with a $3 \mathrm{~dB}$ fibre Bragg grating (FBG) UV written within a single-mode fibre, see figure 1 . The front facet of this FPLD has been anti-reflection coated to reduce reflectivity to a value of $10^{-4}$. The light-emitting half angles (and radius mode) of the FPLD at $1 / e^{2}$ of the maximum intensity are $25^{\circ}(\omega=0.89 \mu \mathrm{m})$ and $30^{\circ}(\omega=0.71 \mu \mathrm{m})$ in the parallel and perpendicular directions opposing the epitaxial surface, respectively.

The use of a new specially designed $50 \mu \mathrm{m}$ workingdistance lensed fibre offers a coupling efficiency of $2 \mathrm{~dB}$. The hyperbolic shape lowers spherical aberrations and offers high coupling efficiency and a long working distance.

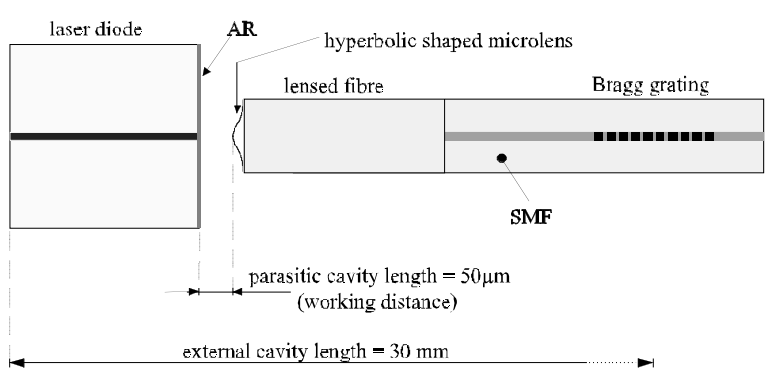

Figure 1. Schematic diagram of an external cavity laser

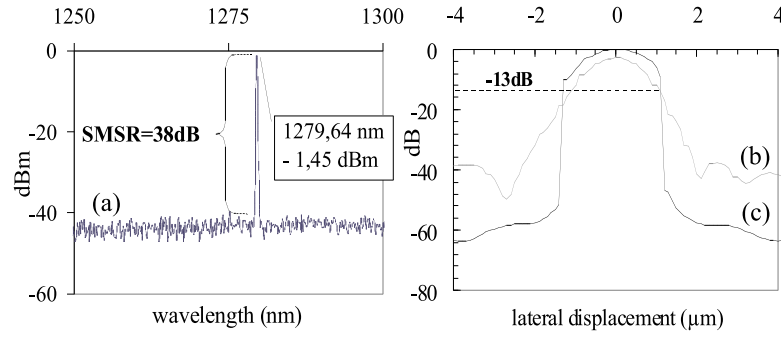

Figure 2. (a) Optical power spectrum of the SECL,

(b) coupling-loss characteristic of a lensed fibre versus lateral displacement and $(c)$ normalized power of the SECL main mode versus lateral displacement.

The resulting single-mode spectrum of the SECL is shown in figure $2(a)$. The mode power is about $700 \mu \mathrm{W}$ for an $80 \mathrm{~mA}$ biased current at $19.7{ }^{\circ} \mathrm{C}$, with a side-mode suppression ratio (SMSR) of $38 \mathrm{~dB}$, a full width half maximum (FWHM) of $0.1 \mathrm{~nm}(17.8 \mathrm{GHz})$ and a relative intensity noise (RIN) of $-150 \mathrm{~dB} \mathrm{~Hz}^{-1}$ at $30 \mathrm{MHz}$.

In order to make sure that the insertion of a coupler would not prevent laser operation, allowable losses in the external 


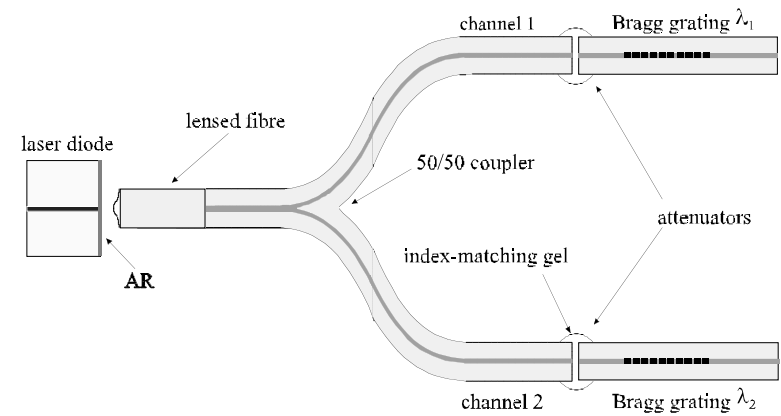

Figure 3. Dual-wavelength source based on an Fabry-Perot laser diode, UV-written gratings and micro-optics.
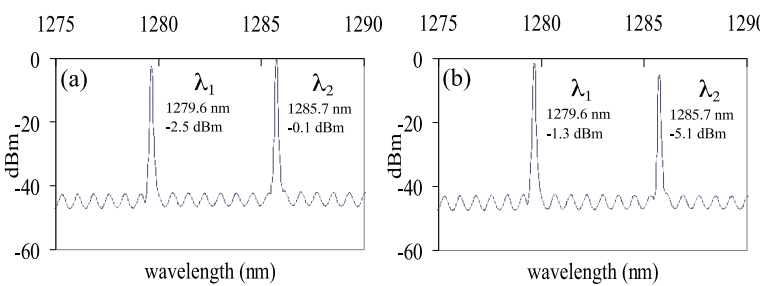

Figure 4. (a) Dual-wavelength output spectrum from the DECL through channel 1. (b) Dual-wavelength output spectrum from the DECL through channel 2.

cavity had to be determined. For this purpose, artificial losses are created by introducing a lateral misalignment between the laser diode and the lensed fibre. The coupling losses versus lateral displacement of the fibre are first characterized, without the Bragg grating, figure 2(b). To connect the laser operation with insertion losses we plot the normalized power of the SECL emission with an isolated main mode (using a FBG) versus identical lateral displacement, see figure 2(c).

According to the abrupt drop of the SECLs emission (figure 2(c)) for a lateral displacement of about $1 \mu \mathrm{m}$, which corresponds to the limit of laser operation, the maximum internal cavity losses are evaluated at $13 \mathrm{~dB}$ while preserving a SMSR of better than $30 \mathrm{~dB}$. These high allowable losses are probably due to the very low internal parasitic optical feedback. As is known, optical feedback generates severe perturbations on the external oscillations of the laser. In our case, the hyperbolic shape of the lensed fibre combined with a large working distance provides very low parasitic feedback. Taking into account the $2 \mathrm{~dB}$ coupling loss, the available budget for inserting a coupler inside the cavity is about $11 \mathrm{~dB}$. This value is well suited for eight-channel laser realization which involves a 1:8 coupler ( $9 \mathrm{~dB}$ loss). In the following, a two-channel laser is developed in order to demonstrate the MECL concept with a common optical gain medium.

\section{Double external cavity laser}

A schematic view of this double external cavity laser (DECL) is represented in figure 3. Two different $3 \mathrm{~dB}$ FBGs are UV written within each coupler's arm with a $6.1 \mathrm{~nm}$ wavelength spacing $\left(\lambda_{2}-\lambda_{1}\right)$. Both external cavity lengths are about $20 \mathrm{~cm}$. In order to control the mode power balance of the DECLs output, a variable attenuator is inserted into each arm.

The resulting output spectra through ports 1 and 2 are shown in figure 4 . The $\mathrm{CW}$ dual-wavelength emission reported corresponds to the two different frequency-selective Bragg reflectivities. Notice that both wavelengths are transmitted through each port.

The SMSR is larger than $35 \mathrm{~dB}$. Mode power ratios from the two ports are different, both wavelengths are differently attenuated according to the FBG of the transmitter arm and the insertion loss of the attenuators. The average output power of each mode is about $0.3-1 \mathrm{~mW}$ for a $60 \mathrm{~mA}$ laserdiode biased current at $19.7^{\circ} \mathrm{C}$, with a FWHM of $0.1 \mathrm{~nm}$, corresponding to the resolution limit of the spectrometer. The measured RIN at $30 \mathrm{MHz}$ is about $Đ 105 \mathrm{~dB} \mathrm{~Hz}^{-1}$ and the mode partition noise (MPN), which is the intensity noise of the isolated mode, reaches about $Đ 95 \mathrm{~dB} \mathrm{~Hz}^{-1}$ for each mode. This extraction is provided by a circulator with an adapted FBG. A single-mode emission can be obtained either by adjusting the biased current or the insertion losses from the attenuator of the opposite channel. The corresponding RIN is then measured at $Đ 150 \mathrm{~dB} \mathrm{~Hz}^{-1}$.

This device is expected to be less sensitive to temperature than the DBR laser diode due to the lower temperature dependence of the Bragg grating: $15 \mathrm{pm} \mathrm{K}^{-1}$ compared with $100 \mathrm{pm} \mathrm{K}^{-1}$ for the DBR laser diode. Future measurements should point out the low temperature dependence of this kind of device even if we take into account the displacement of the peak gain of the external cavity laser diode as a function of temperature.

\section{Conclusion}

We have demonstrated the possibility of using couplers in multi-wavelength sources thanks to a well-adapted lensed fibre. The resulting emission power reaches $0 \mathrm{dBm}$ for each wavelength with a SMSR $>35 \mathrm{~dB}$. The interest in separated cavities stems from the ability to control relative dualwavelength power with attenuators placed in front of each Bragg grating, in contrast to both gratings in series in a single channel. Consequently, this device offers the opportunity to analyse laser operation according to the respective efficiency of each Bragg reflector. Consequently, separated cavities offer the opportunity to analyse the behaviour of the device as a function of the respective efficiency of each Bragg reflector. RIN measurements show a $45 \mathrm{~dB}$ increase in noise for DECL total radiated power compared with the SECL, and a MPN which returns $55 \mathrm{~dB}$ extra noise to isolated modes.

This very important extra noise compared with SECL is a severe limitation for optical communication systems. Future bit error rate measurements should allow one to establish the frequency modulation range where the DECL is suitable for simultaneous use of both wavelengths. According to the low measured RIN for the single-mode DECL, further studies will also concern commutation between both wavelengths by bias current internal modulation or external optical modulation. This commutation between the wavelengths $\lambda_{1}$ and $\lambda_{2}$ is expected to be achievable by either varying the bias current of the laser diode (called internal modulation) or by injecting an external signal of wavelength $\lambda_{1}$ or $\lambda_{2}$ into one channel of the DECL (called external optical modulation). We have begun to observe such behaviour but have yet to confirm this using other experiments. 
The authors would like to thank H Poignant for the UVwritten gratings, J Landreau for the anti-reflection coatings and A Le Corre and D Pavy for fruitful discussions.

\section{References}

[1] Roh S D, Swint R B, Jones A M, Yeoh T S, Huber A E, Hugues J S and Coleman J J 1999 Dual-wavelength asymmetric cladding InGaAs-GaAs ridge waveguide distributed Bragg reflector lasers IEEE Photonics Technol. Lett. 11 15-17
[2] Le Gall F, Mottet S, Devoldere N and Landreau J External cavity laser for DWDM access network (Euro. Conf. on Optical Communication, ECOC'98) pp 285-6

[3] Burns D, Hay G and Sibbett W 1993 Dual-wavelength external cavity semiconductor lasers Conf. on Lasers and Electro-optics, 1993 pp 445-6

[4] Zhao Y and Shu C 1998 Selectable dual-wavelength pulses generated from a laser diode using external feedback from a two-chromatic fibre grating Appl. Phys. Lett. 73 2402-4

[5] Wang D N and Shu C 1997 Dual-wavelength picosecond pulse generation using a single grating and a Michelson interferometer in a self-injection seeding scheme Electron. Lett. 33 424-5 